\title{
Proliferation and differentiation in the human fetal endocrine pancreas
}

\author{
L. B ouwens ${ }^{1}$, W. G . L u ${ }^{1}$, R . D e Krijger ${ }^{2}$ \\ ${ }^{1}$ Laboratory of Experimental Pathology, Free University Brussels (V. U. B.), Brussels, Belgium \\ ${ }^{2}$ Department of Pathology, University Hospital Dijkzigt, Rotterdam, The Netherlands
}

Summary The morphogenesis and growth of the endocrine pancreas has not been well investigated in man although it represents an important issue in diabetology. We examined human fetal pancreas from 12 to 41 weeks of gestation immunocytochemically to evaluate proliferative activity with the Ki-67 marker, and cytodifferentiation with cytokeratin 19 (ductal cells), synaptophysin (all endocrine cells), and insulin, glucagon, somatostatin and pancreatic polypeptide (islet cell types). Ki-67 labelling was found in all these cell types but was much higher in ductal cells than in islet cells. An intermediate population expressed synaptophysin but lacked islet hormones. With increasing gestational age the Ki-67 labelling index decreased from 17 to $4 \%$ in ductal cells, from 9 to
$1 \%$ in synaptophysin-positive cells, and from 3 to $0.1 \%$ in insulin- or glucagon-positive cells. From 12 to 16 weeks, all epithelial cells including the endocrine islet cells expressed cytokeratin 19. Thereafter cytokeratin 19 expression decreased and eventually disappeared from most islet cells, whereas strong expression remained in the ductal cells. We show that differentiated human islet cells have only very limited proliferative capacity, and we demonstrate the existence of transitional differentiation stages between ductal and islet cells. [Diabetologia (1997) 40: 398404]

Keywords Islets of Langerhans, beta cells, development, neogenesis, growth.
The mammalian endocrine pancreas is histologically organized in islets of Langerhans which are composed of four endocrine cell types characterized by the expression of insulin, glucagon, somatostatin or pancreatic polypeptide. The population dynamics of these cells have generated considerable interest since the renewal and growth of the insulin-expressing beta cells in particular represents a critical issue in diabetology. The numerical increase or renewal of these cells can occur in two ways, namely by replication of differentiated endocrine cells within the islet and by

Received: 8 November 1996 and in revised form: 7 January 1997

Corresponding author: Prof. Dr. L. Bouwens, Laboratory of Experimental Pathology, Free University Brussels (V.U.B.), Laarbeeklaan 103, B-1090 Brussels, Belgium

A bbreviations: PBS, Phosphate buffered saline; LI, labelling index. neogenesis from undifferentiated precursor cells located in the excretory ducts [1]. Rodent studies have demonstrated that in the fetal and perinatal period neogenesis from (ductal) precursor cells is quantitatively the major mechanism of endocrine cell generation [2-4]. In the normal postnatal rodent pancreas there is still some growth of the endocrine pancreas [5], which must be added to the renewal rate or the physiologically determined replacement of the cells. The extent of the latter is unknown since there is no information on the life span of islet cells. The relative importance of replication and neogenesis for physiological growth and renewal are not yet known. Appropriate stimulation of ductal cells in adult rodents leads to increased islet neogenetic activity in ductules [6-8]. Thus, normal adult pancreas retains a population of islet stem cells [1].

Much less is known of the islet cell population dynamics in larger mammals and in particular in the human pancreas. Although studies of human fetuses 
have suggested that islets originate from ductules [911], this contention is mainly based on topographical relationships between both tissue structures and not on an analysis of differentiation markers and transitional forms. Data are also lacking on the proliferative activity of human islet cells. Therefore we conducted an immunohistochemical study on fetal human pancreas using Ki-67 as a marker of cell proliferation, cytokeratin 19 as a ductal cell marker and the four hormones as islet cell markers. Synaptophysin was taken as a marker of all endocrine cells.

\section{Materials and methods}

Tissue collection and preparation. Human fetal pancreata $(n=24)$ were obtained from legal abortion between 12 and 18 weeks of gestation with permission of the local ethical committee (University Hospital Dijkzigt) (Table 1). Gestational age was determined by biparietal diameter from echographic measurement. Abortions were induced mechanically, resulting in a warm ischaemia time of 15-25 min. Pancreata of older fetuses and neonates were obtained from spontaneous abortions and deceased premature births at autopsy, less than $12 \mathrm{~h}$ after death. The neonates died of causes not related to pancreas pathology. Whole pancreata or tail parts of the pancreata were fixed in $4 \%$ buffered formalin overnight [12]. After fixation, tissues were embedded in paraffin according to routine procedures.

I mmunocytochemistry. Paraffin sections (3-5 $\mu \mathrm{m}$ thick) were mounted onto 3-aminopropyltriethoxy-silane-coated slides and dried overnight at $37^{\circ} \mathrm{C}$. After deparaffinization and rehydration, sections were pre-treated with $0.1 \%$ trypsin (Sigma, St. Louis, Mo., USA) solution for $5 \mathrm{~min}$ and then rinsed in distilled water. Then slides were placed in Pyrex glass jars filled with $0.01 \mathrm{~mol} / \mathrm{l}$ citrate buffer $(\mathrm{pH}$ 6.0) and incubated three times for $3 \mathrm{~min}$ at the maximum power $(750 \mathrm{~W})$ in a household microwave oven (Whirlpool AVM602; Stockholm, Sweden). After this microwave antigen retrieval, the sections were allowed to cool down to room temperature and washed with phosphate-buffered saline (PBS). Then slides were incubated overnight with monoclonal antibody to Ki-67 (clone MIB-1; Immunotech, Marseille, France) diluted (1:50) in PBS. The monoclonal MIB-1 antibody reacts with the Ki-67 nuclear antigen (345 and $395 \mathrm{kDa}$ in Western blot) of proliferating cells and has often been used in cytokinetic studies; microwave treatment is necesary to retrieve the antigenicity of the protein in paraffin-embedded tissue [13-18]. The streptavidin-biotinperoxidase complex (ABC)-method (Dako, Glostrup, Denmark) was used with diaminobenzidine as chromogen. For the second step of double staining, we applied monoclonal anti-cytokeratin 19 (clone RCK108, Dako) to detect pancreatic ductal epithelium (ducts and centroacinar cells), polyclonal antisynaptophysin (Dako) to detect all endocrine cells, monoclonal antibodies to insulin (clone AE9D6, BioGenex, San Ramon, Calif., USA), glucagon (clone Glu-001; Novo Nordisk, Bagsvaerd, Denmark), somatostatin (clone SOM-08; NovoNordisk), or a polyclonal antibody to pancreatic polypeptide (Prof. R.E. Chance; Lilly Research, Indianapolis, Ind., USA). The monoclonal RCK108 antibody reacts with a $40 \mathrm{kDa}$ cytoskeletal protein which represents the smallest human keratin found in most simple epithelia; it does not recognize other intermediate filament proteins (Dr. F. Ramaekers, Maastricht,
Table 1. Fetal pancreata used in this study

\begin{tabular}{llllllllllllllll}
\hline $\begin{array}{l}\text { Gestational } \\
\text { age (weeks) }\end{array}$ & 12 & 14 & 15 & 16 & 18 & 19 & 20 & 21 & 24 & 25 & 34 & 35 & 40 & 41 \\
$\begin{array}{l}\text { Number } \\
\text { of cases }\end{array}$ & 1 & 1 & 2 & 1 & 4 & 3 & 1 & 1 & 1 & 2 & 2 & 1 & 3 & 1 \\
\hline
\end{tabular}

The Netherlands, personal communication). We used $\mathrm{ABC} /$ alkaline phosphatase complex (Dako) and New Fuchsin as chromogen for the second sequence. The immunocytochemical staining was controlled by (a) the use of secondary reagents only (omitting the primary antibodies), (b) the development of enzymatic activities alone as a control for endogenous activity, and (c) the use of murine subclass-matched unrelated primary monoclonal antibodies or appropriate normal serum. All control assays revealed negative results and are not mentioned further. For Ki-67, control stainings were also performed on sections from human intestine. As expected, many positive nuclei appeared in the intestinal crypts (= proliferative compartment) whereas the tips of the villi were negative.

Quantitative analysis. By definition, the Ki-67 labelling index (LI) of ductal epithelium, endocrine cells, insulin-expressing beta and glucagon-expressing alpha cells were calculated as follows:

\section{LI-Duct $(\%)=$ \\ Cytokeratin 19 and Ki-67 double positive cells Total cytokeratin 19 positive cells}

LI-Endocrine $(\%)=$

Synaptophysin and Ki-67 double positive cells Total synaptophysin positive cells

LI-Beta (or alpha) $(\%)=$

Insulin (or glucagon) and Ki-67 double positive cells Total insulin (or glucagon) positive cells $\times 100$

To determine the LI, 1000 cells (cytokeratin 19, synaptophysin) or 500-1000 cells (insulin, glucagon) were counted per sample.

Statistical analyses were performed using the Student's paired t-test. The polynomial trend analysis and exponential curves [19] showing the relationship between Ki-67 labelling index and gestational age were calculated with Cricket Graph 1.3 software for Macintosh (Cricket Software, Malvern, Penn., USA).

\section{Results}

Proliferation. After double immunohistochemical staining, the cell proliferation marker Ki-67 could be detected in nuclei from insulin- and glucagon-positive cells (Fig. 1), and also in somatostatin- and pancreatic polypeptide-positive cells (not shown). The neuroendocrine marker synaptophysin was used to count the Ki-67 labelling index (LI) of all endocrine cells (Fig.1). Synaptophysin-positive nerves were recognized morphologically and were not included in the 

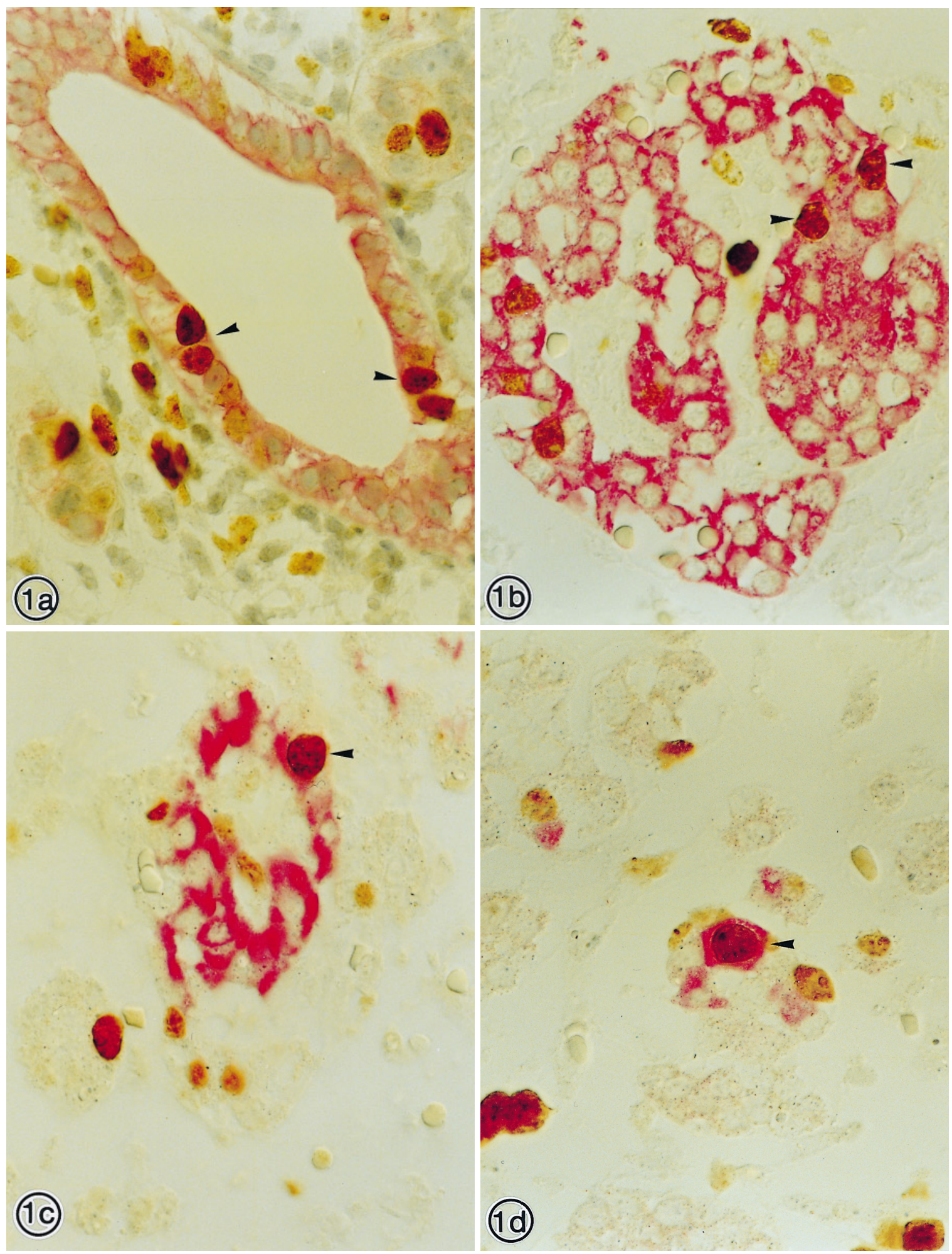

Fig. 1A - D. Immunocytochemical double staining of fetal pancreata from 21 weeks of gestation for the proliferation marker Ki-67 (positive nuclei are stained brown) and the differentiation markers (cytoplasm stained red): (A) cytokeratin 19, a marker for ductal epithelium; (B) synaptophysin, a marker for endocrine cells; (C) insulin, a beta-cell marker; (D ) glucagon, an alpha-cell marker. Arrowheads point to some doublepositive cells. $\times 660$

counts. Ductal epithelial cells were characterized by cytokeratin 19-staining (Fig. 1) and showed a higher LI than the synaptophysin-positive or hormone-positive cells (Fig. 2). With increasing gestational age, the LI of ductal cells decreased from $17.3 \%$ at 12 weeks to $4.4 \%$ at 41 weeks, whereas the LI of synaptophysin-positive endocrine cells decreased from 9 to $1.2 \%$ in the same period (Fig. 2). Polynomial trend 

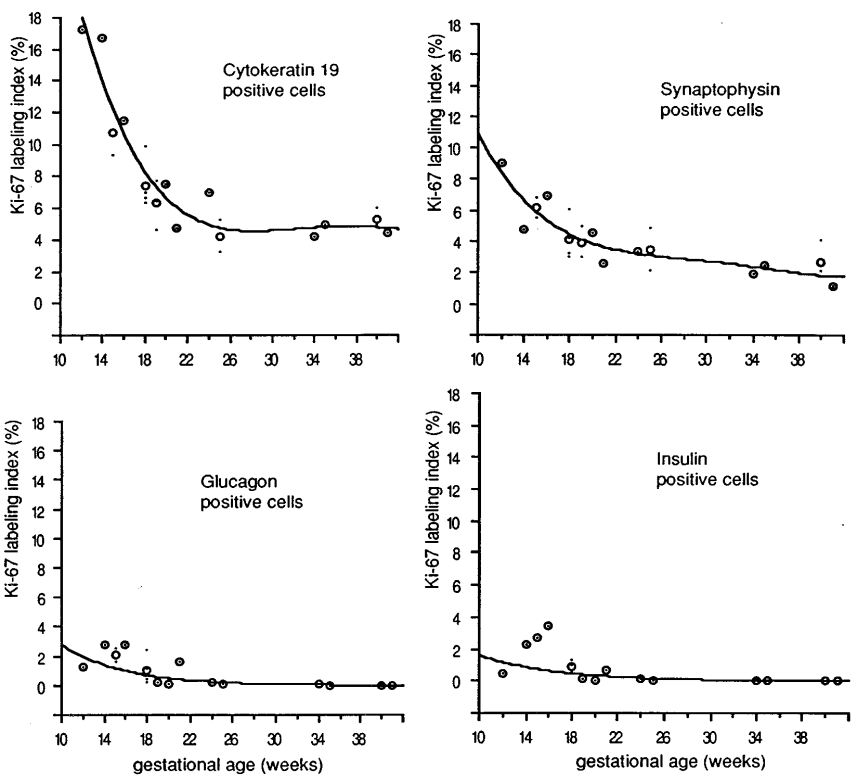

Fig. 2. Relationship between the Ki-67 labelling index of cytokeratin 19-, synaptophysin-, insulin-, and glucagon-expressing cells with gestational age. Circles represent the mean and points indicate individual samples (see Table 1 for number of samples). Note the difference in scale (Y-axis) between the two upper and the two lower pannels

analysis of LI compared to gestational age gives the best fit for the results $\left(R^{2}=0.92\right.$ and 0.83 , respectively for ductal and synaptophysin-positive cells) and shows similar curves, with the LI of ductal cells being approximately double that of the synaptophysin-positive cells $(p<0.001)$ (Fig. 2). The LI of insulin-expressing beta cells and glucagon-expressing alpha cells showed a peak at 14-16 weeks of gestation, approximately $3 \%$ of the cells being positive for Ki67. The LI of beta cells and alpha cells sharply dropped to a very low level 24 weeks onward, namely 0.1 and $0.2 \%$, respectively. Exponential curves give the best fit for the Ki-67 LI of beta cells and alpha cells compared to gestational age $\left(R^{2}=0.61\right.$ and 0.78$)$ (Fig. 2). Both curves are similar and there were no statistical differences between the LI of beta cells and alpha cells $(p>0.6)$. Statistical analysis showed that the LI of beta cells and alpha cells was significantly lower than the LI of synaptophysin-positive endocrine cells and ductal cells $(p<0.001)$. Somatostatin- and pancreatic polypeptide (PP)-expressing cells showed a very low proliferative activity comparable to that of beta and alpha cells, but their LI could not be counted reliably due to their low frequency in the tissue. A very high proliferative activity was noted in the mesenchymal cells between 12 and 24 weeks.

Differentiation. In all investigated fetal pancreata we found cells immunoreactive for insulin, glucagon, somatostatin and PP, with the exception of a 12-weekold fetus which did not present PP-reactive cells.

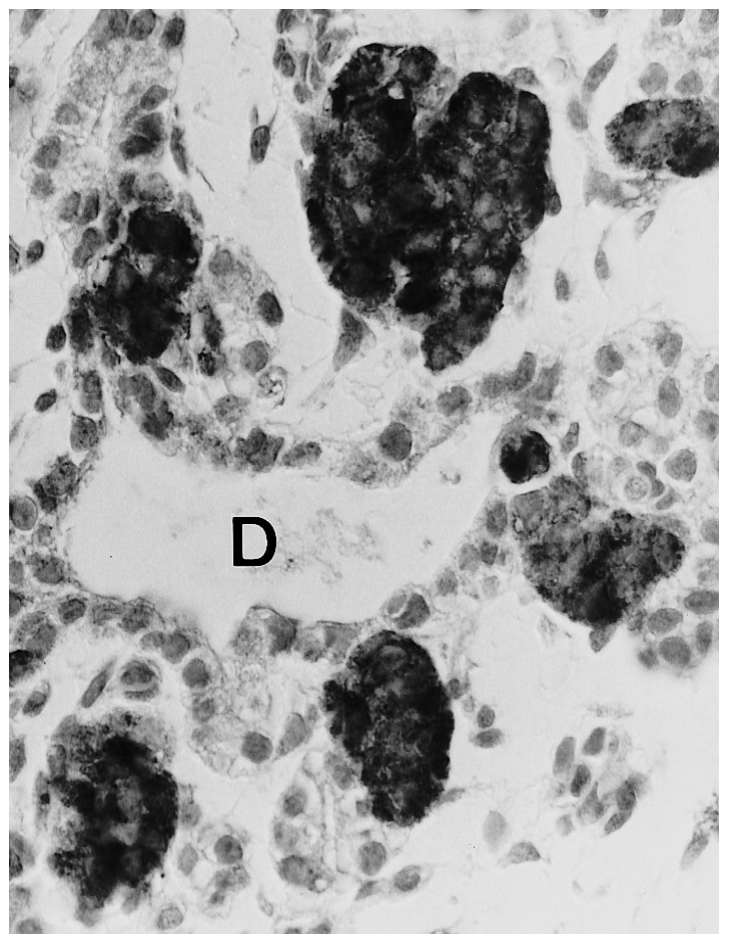

Fig. 3. Single immunocytochemical staining for synaptophysin ( = endocrine marker) on fetal pancreas from 16 weeks of gestation. Endocrine cell clusters of varying size are found around a duct (D). $\times 660$

Cells lining the ducts and ductules strongly expressed cytokeratin 19 in all cases. From 12 to 16 weeks of gestation, the pancreas consisted of branching ductules and epithelial buds that were embedded in densely cellular mesenchymal tissue. All epithelial cells, including the endocrine cells at this stage expressed cytokeratin 19 whereas mesenchymal cells were negative. Hormone-expressing cells were found as single cells or small clusters arranged within or alongside the ductular lining, or as small (vascularized) islets that were in direct contact with one or more surrounding ducts (Fig.3). In the islets, most endocrine cells showed weaker cytokeratin staining as compared to the ducts (Fig. 4). Double immunocytochemical staining on the same section (Fig. 4A) or on consecutive sections (Fig. 4B-D) clearly showed the presence of islet cells co-expressing cytokeratin 19 with either insulin, glucagon or synaptophysin, i.e. transitional differentiation forms between ductal epithelium and islet cells.

From 18 to 24 weeks, there was a further decrease of cytokeratin 19 expression in the islets, whereas ductal structures remained intensely stained. However, single endocrine cells and small clusters associated with ductules still showed relatively strong cytokeratin 19 staining. Islets were frequently seen to contain hormone-negative cells which were intensely stained for cytokeratin 19 and which were found in the centre as well as in the periphery of the islets 

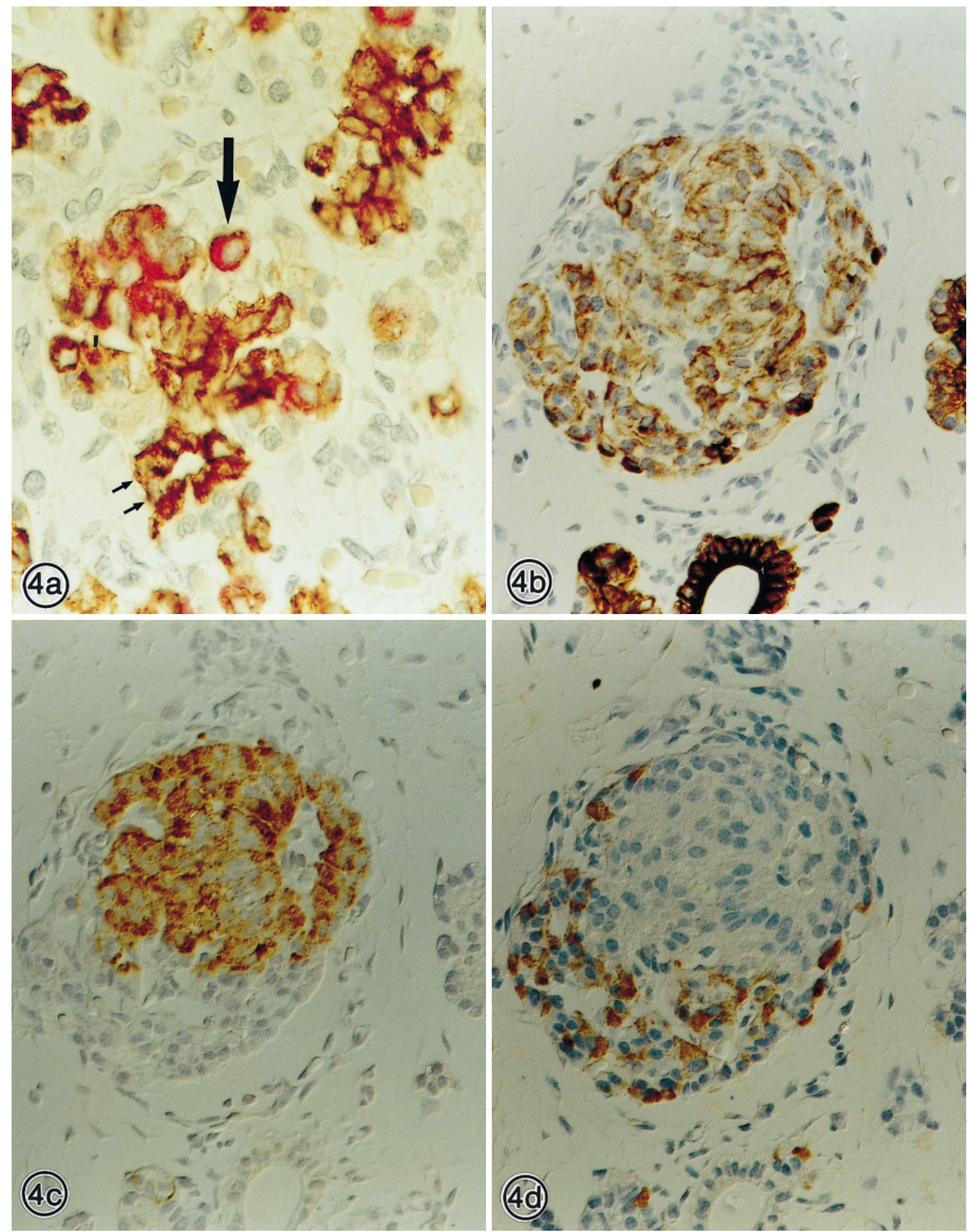

Fig. 4A - D. Pancreas at 16 weeks of gestation. A : double immunocytochemical staining for cytokeratin 19 (brown) and insulin (red). Arrow points to a double-positive transitional cell; double arrow points to a duct; $\times 660$. B - D : Consecutive sections from an islet single-stained for (B ) cytokeratin $19,(\mathbf{C})$ insulin, and (D) glucagon. $\times 210$

(not shown). There was still a lot of mesenchymal tissue surrounding the epithelial elements, but the density of mesenchymal cells was decreased compared to the period between 12 and 16 weeks.

From 24 to 41 weeks, most islet cells were cytokeratin 19-negative whereas all ductal and centroacinar cells remained strongly positive (Fig.5). Nevertheless, cells expressing cytokeratin 19 could still be found scattered at low frequency in some islets (not shown). At this stage, the centroacinar and ductal cells (i.e. cytokeratin 19-positive cells) represented approximately one-third of all pancreatic epithelial 


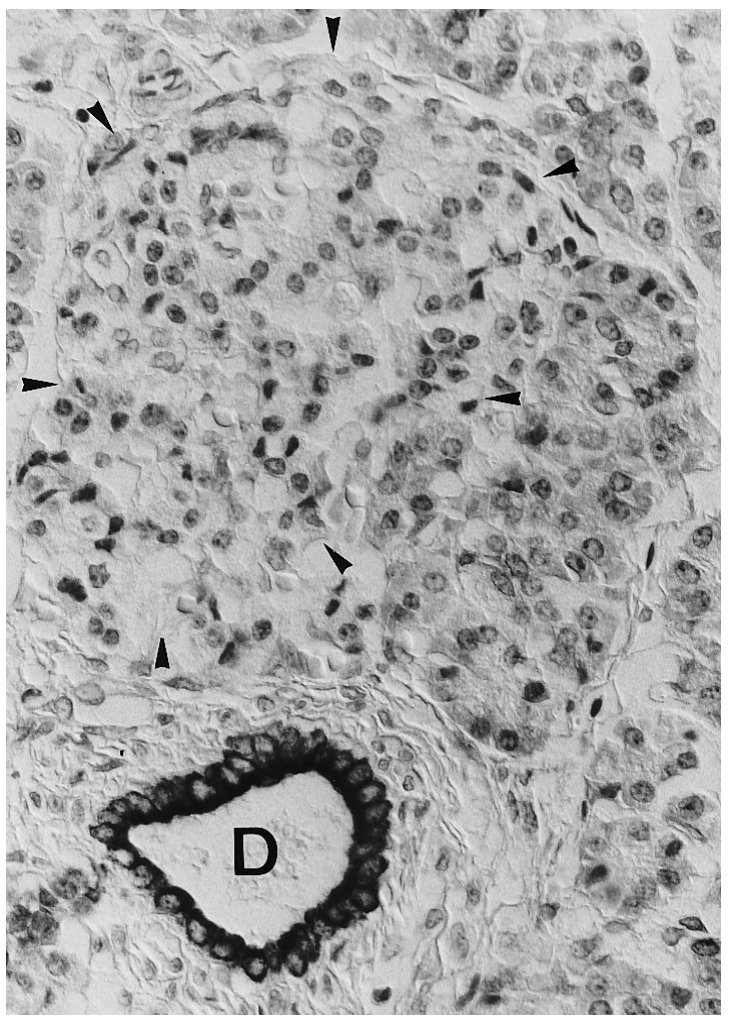

Fig. 5. Cytokeratin 19 staining of pancreas from 34 weeks of gestation showing a negative islet (arrowheads) and a positive duct (D). $\times 660$

cells. Mesenchymal tissue became restricted to the connective tissue space around larger ducts and blood vessels and to a minimal interacinar space, as it is seen in normal pancreas from adults.

\section{Discussion}

This represents to the best of our knowledge the first study documenting the proliferative activity of islet cells and their precursors in the human fetal pancreas. A previous study using enzymatically dissociated and overnight cultured human midgestational pancreas failed to demonstrate incorporation of the thymidine-analogue bromodeoxyuridine in endocrine cells [12]. This apparent absence of proliferation in fetal islet cells could have been related to the isolation and culture procedure. We used immunohistochemical staining of Ki-67 to detect proliferating human fetal cells in vivo. Ki-67 has been shown in many studies to represent a useful operational marker of cell proliferation [13-18]. Double immunohistochemical staining for $\mathrm{Ki}-67$ and islet hormones revealed proliferative potential in all islet cell types before 20 weeks of gestation, but thereafter the hormone-positive cells apparently ceased to proliferate (LI around $0.1 \%)$. The observed LI of synaptophysin-positive endocrine cells decreased from 9 to $1.2 \%$ with increasing gestational age but was always higher than that of islet-hormone-positive cells. This suggests that a subpopulation of synaptophysin-positive/ hormone-negative cells exists which have a higher proliferative activity than the more differentiated hormone-positive cells.

The Ki-67 LI is thought to approximate the growth fraction of a cell population, i.e. the fraction of cells which are cycling [13]. In rodents, the growth fraction of islet cells has been estimated as $10 \%$ in the late-gestational rat fetus and thereafter decreased to $3 \%$ in young adults [20]. In these animals, the endocrine pancreas rapidly grows during the last few days of gestation [5, 21], whereas in man the growth process takes several months namely between 12 and 40 weeks [22]. The very low Ki67-LI (around $0.1 \%$ ) which we observed in human late gestational beta cells may indicate that this proliferative activity is even lower than in rodents. This very low proliferative activity confirms previous in vitro studies on islet cells from fetal $[12,23]$ or adult [24] human pancreas which show very low baseline proliferative levels between 0 and $0.1 \%$ after bromodeoxyuridine-labelling. The fetal human endocrine pancreas shows its highest growth rate between 21 and 40 weeks [22]. The very low mitotic activity of the islet cells that we observed during this period demonstrates the importance of islet cell neogenesis from hormone-negative precursor cells, or stem cells. The importance of neogenesis has also been demonstrated in fetal and neonatal rat pancreas, where $80 \%$ or more of the beta cells are generated from precursors rather than from auto-replication $[4,20]$.

The pancreatic stem cells responsible for islet cell neogenesis are presumed to be located in the ductal compartment. We characterized ductal cells in this study by cytokeratin 19 staining. We have found that this cytoskeletal protein represents a very specific and stable marker of ductal cells, from centroacinar to main duct, in adult human pancreas (unpublished observations), and this confirms other studies [25, 26]. Fetal ductal cells showed a much higher proliferative activity than the hormone-positive alpha and beta cells. Although the ductal LI decreased with gestational age, it remained relatively high throughout gestation $(>4 \%)$. The synaptophysin-positive cells showed LI values intermediate between ductal and hormone-positive cells. This indicates that they may represent an intermediate differentiation stage between ductal and islet cells.

During early fetal development all pancreatic epithelial cells were found to express cytokeratin 19, confirming the ductal nature of pancreatic stem cells. By using the ductal cell marker cytokeratin 19 in conjunction with endocrine markers synaptophysin and islet hormones, our observation of transitional cells co-expressing these ductal and endocrine markers represents the first direct demonstration of this 
differentiation step and of the ductal nature of human islet stem cells. During the course of development, cytokeratin 19 expression was gradually lost from the differentiating endocrine islet cells. However, a small number of islet cells expressing cytokeratin 19 remained present indicating ongoing islet cell neogenesis throughout fetal development. The possibility that such precursor cells remain present in postnatal human islets should be further explored.

In conclusion, this study demonstrates the importance of islet cell neogenesis from ductal precursors in human fetal pancreas. Differentiated human islet cells appear to possess only very limited mitotic potential, even in the fetus.

A cknowledgements. This work was supported by grants from the Belgian National Fund for Scientific Research (FGWO nrs. G.0041.96 and 3.0093.90).

\section{References}

1. Bouwens L, Klöppel G (1996) Islet cell neogenesis. Virchows Archiv 427: 553-560

2. Eriksson U, Swenne I (1982) Diabetes in pregnancy: growth of the fetal pancreatic B-cells in the rat. Biol Neonate 42: 239-248

3. Hellerström C (1984) The life story of the pancreatic $\beta$ cell. Diabetologia 26: 393-400

4. Bouwens L, Wang RN, De Blay E, Pipeleers DG, Klöppel $\mathrm{G}$ (1994) Cytokeratins as markers of ductal cell differentiation and islet neogenesis in the neonatal rat pancreas. Diabetes 43: 1279-1283

5. McEvoy RC, Madson KL (1980) Pancreatic insulin-, glucagon-, and somatostatin-positive islet cell populations during the perinatal development of the rat, I. Morphometric Quantitation. Biol Neonate 38: 248-254

6. Rosenberg L, Clas D, Duguid W (1990) Trophic stimulation of the ductal /islet cell axis: a new approach to the treatment of diabetes. Surgery 108: 191-197

7. Gu D, Sarvetnick N (1993) Epithelial cell proliferation and islet neogenesis in IFN-g transgenic mice. Development 118: 33-46

8. Wang RN, Klöppel G, Bouwens L (1995) Duct- to islet-cell differentiation and islet growth in the pancreas of duct-ligated adult rats. Diabetologia 38: 1405-1411

9. Falin LI (1967) The development and cytodifferentiation of the islets of Langerhans in human embryos and foetuses. Acta Anat 68: 147-168

10. Like AA, Orci L (1972) Embryogenesis of the human pancreatic islets: a light and electron microscopic study. Diabetes 21 [Suppl 2]:511-534

11. Clark A, Grant AM (1983) Quantitative morphology of endocrine cells in human fetal pancreas. Diabetologia 25: $31-$ 35
12. De Krijger RR, Aanstoot HJ, Kranenburg G, Reinhard M, Visser WJ, Bruining GJ (1992) The midgestational human fetal pancreas contains cells coexpressing islet hormones. Dev Biol 153: 368-375

13. Van Dierendonck JH, Keijzer R, Van de Velde CJH, Cornelisse CJ (1989) Nuclear distribution of the Ki-67 antigen during the cell cycle: comparison with growth fraction in human breast cancer cells. Cancer Res 49: 2999-3006

14. Brown DC, Gatter KC (1990) Monoclonal antibody Ki-67: its use in histopathology. Histopathol 17: 489-503

15. Scott RJ, Hall HA, Haldane JS, Van Noorden S, Price Y, Lane DP, Wright NA (1991) A comparison of immunohistochemical markers of cell proliferation with experimentally determined growth fraction. J Pathol 165: 173-178

16. Gerdes J, Lemke H, Baisch H, Wacker H, Schwab U, Stein H (1983) Cell cycle analysis of a cell proliferation-associated human nuclear antigen defined by the monoclonal antibody Ki-67. J Immunol 133: 1710-1715

17. Cattoretti G, Becker M, Key G, Duchrow M, Schlüter C, Galle J, Gerdes J (1992) Monoclonal antibodies against recombinant parts of the Ki-67 antigen (MIB 1 and MIB 3) detect proliferating cells in microwave-processed formalin-fixed paraffin sections. J Pathol 168: 357-363

18. Cohen MB, Waldman FM, Carroll PR, Kerschmann R, Chew K, Mayall BH (1993) Comparison of five histopathologic methods to assess cellular proliferation in transitional cell carcinoma of the urinary bladder. Hum Pathol 24: 772778

19. Armitage P, Berry G (1987) Statistical methods in medical research, 2nd edn. Blackwell Scientific Publication, Oxford

20. Swenne I (1983) Effects of aging on the regenerative capacity of the pancreatic $\beta$-cell of the rat. Diabetes 32:14-19

21. Kaung HC (1994) Growth dynamics of pancreatic islet cell population during fetal and neonatal development of the rat. Dev Dyn 200: 163-175

22. Stefan Y, Grasso S, Perrelet A, Orci L (1983) A quantitative immunofluorescent study of the endocrine cell populations in the developing human pancreas. Diabetes 32: 293 301

23. Otonkoski T, Beattie G M, Rubin J S, Lopez A D, Baird A, Hayek A (1994) Hepatocyte growth factor/scatter factor has insulinotropic activity in human fetal pancreatic cells. Diabetes 43: 947-953

24. Hayek A, Beattie GM, Cirulli V, Lopez AD, Ricordi C, Rubin JS (1995) Growth factor/matrix-induced proliferation of human adult b-cells. Diabetes 44: 1458-1460

25. Kasper M, Hahn von Dorsche H, Stosiek P (1991) Changes in the distribution of intermediate filament proteins and collagen IV in fetal and adult human pancreas; I. Localization of cytokeratin polypeptides. Histochemistry 96: 271277

26. Schüssler MH, Skoudy A, Ramaekers F, Real FX (1992) Intermediate filaments as differentiation markers of normal pancreas and pancreas cancer. Am J Pathol 140: 559568 